\title{
Maximum Power Point Tracking of PV System Based on Machine Learning
}

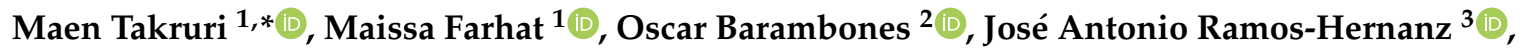 \\ Mohammed Jawdat Turkieh ${ }^{1}$, Mohammed Badawi ${ }^{1}$, Hanin AlZoubi ${ }^{1} \mathbb{D}$ and \\ Maswood Abdus Sakur ${ }^{1}$ \\ 1 Department of Electrical, Electronics and Communications Engineering, American University of Ras $\mathrm{Al}$ \\ Khaimah, Ras Al Khamah, UAE; maissa.farhat@aurak.ac.ae (M.F.); mohammed.turkieh@aurak.ac.ae (M.J.T.); \\ mohammed.badawi@aurak.ac.ae (M.B.); haneen.alzoubi@aurak.ac.ae (H.A.); \\ maswood.abdussakur@aurak.ac.ae (M.A.S.) \\ 2 Systems Engineering and Automatic Control Department, Faculty of Engineering Vitoria-Gasteiz, University \\ of the Basque Country, 01006 Vitoria-Gasteiz, Spain; oscar.barambones@ehu.eus \\ 3 Electrical Engineering Department, Faculty of Engineering Vitoria-Gasteiz, University of the Basque \\ Country, 01006 Vitoria-Gasteiz, Spain; josean.ramos@ehu.eus \\ * Correspondence: maen.takruri@aurak.ac.ae
}

Received: 28 December 2019; Accepted: 1 February 2020; Published: 5 February 2020

\begin{abstract}
This project studies the conditions at which the maximum power point of a photovoltaic (PV) panel is obtained. It shows that the maximum power point is very sensitive to external disturbances such as temperature and irradiation. It introduces a novel method for maximizing the output power of a PV panel when connected to a DC/DC boost converter under variable load conditions. The main contribution of this work is to predict the optimum reference voltage of the PV panel at all-weather conditions using machine learning strategies and to use it as a reference for a Proportional-Integral-Derivative controller that ensures that the DC/DC boost converter provides a stable output voltage and maximum power under different weather conditions and loads. Evaluations of the proposed system, which uses an experimental photovoltaic dataset gathered from Spain, prove that it is robust against internal and external disturbances. They also show that the system performs better when using support vector machines as the machine learning strategy compared to the case when using general regression neural networks.
\end{abstract}

Keywords: forecasting; support vector regression; general regression neural network; photovoltaic power system; renewable energy; estimator; boost-converter; PID controller

\section{Introduction}

Electric energy is essential to our daily lives. Traditionally, the generation of electric energy involved the combustion of fossil fuels which led to major problems to human beings and planet Earth's environment. Accordingly, efforts have recently been focused on finding alternative ways to generate electricity from clean and sustainable energy resources such as sunlight [1].

Using photovoltaic (PV) systems, sunlight can be converted into electrical energy that can be instantly used, stored or connected to the grid [2]. Unfortunately, the initial implementation costs of PV systems are relatively high. In addition, the efficiency of the energy conversion process in PV systems is relatively low [3].

The energy output is sensitive to the variations in weather conditions [4]. Variations in cloud cover, fog, and heat affect the PV system conversion efficiency. Dust and other particles floating in the air or covering the panel can drastically decrease the efficiency of the power conversion process as 
well [5]. Consequently, many research efforts are focused on finding ways to drive the PV panels to their maximum output power at all weather conditions, thus ensuring their profitability [3].

Studying the nonlinear characteristics of the PV system, scientists noticed that for a given pair of solar insolation and ambient temperature values, there exists a unique operating point (output voltage) at which the PV output power is at its maximum. Any change in the output voltage because of the change of load or other reasons will cause the PV panel to produce less power than the maximum [6]. The output power is also dependent on solar radiation and temperature [7]. All of the above make the continuous system operation at the maximum output power point an extremely difficult task. The challenge here is to obtain an equilibrium operating point such that the PV panel maximum power point matches the load demands [8].

Several efforts have been made to control the operation of PV systems at maximum power. Perturb and Observe ( $\mathrm{PaO}$ ) [3] and Incremental Conductance (IC) were among the earliest methods to address the problem. Both methods are widely used because of the ease of their implementation. Yet, they have their own drawbacks, which include uncertainty due to sensitivity to abrupt variations in the weather conditions $[3,9]$ and oscillations around the operating point $[10,11]$.

Different approaches reported in literature addressed the same problem, i.e., aiming to enhance the results achieved by the PaO. In addition to fuzzy logic-based methods [12-15], computational optimization methods such as swarm optimization [16] and ant colony optimization [17] were used to improve the speed and stability against the variability of irradiance.

Artificial neural networks (ANNs) $[9,18-21]$ focused methods were among the approaches followed to solve the problem. Being well-known machine learning algorithms, ANNs ability to model nonlinear functions enabled the accurate estimation of PV panel reference voltage corresponding to the maximum output power. Besides accuracy in estimating the maximum power point, ANN-centered methods showed a fast response in the testing phase.

Another machine learning algorithm that has been used in relation to renewable energy is support vector regression (SVR) [4,22-25]. In [6], it was successfully used to predict the PV reference voltage corresponding to maximum output power. Unlike ANNs, which converge at local minima, SVR converges at global minima [26] marking it as a favorable candidate for modeling functions and for prediction purposes [6].

This project studies the conditions at which the maximum power point of a PV panel is obtained. It shows that the maximum power point is very sensitive to external disturbances such as temperature and irradiation. It introduces a novel method for maximizing the output power of a PV panel when connected to a DC/DC boost converter under variable load conditions. The main contribution of the work is to predict the optimum reference voltage of the PV panel at all-weather conditions using machine learning strategies and to use it as a reference for a Proportional-Integral-Derivative (PID) controller that ensures that the DC/DC boost converter provides a stable output voltage and maximum power under different weather conditions and loads. The system performance is verified over an experimental photovoltaic dataset gathered from Spain. It includes temperature, solar irradiance, output current, voltage, and power for a period of one year. Evaluations of the proposed system prove its robustness against internal and external disturbances. It also shows that the system performs better when using support vector machines as the machine learning strategy as opposed to the case when using artificial neural networks.

\section{Proposed System}

The proposed maximum power point tracking (MPPT) system block diagram is shown in Figure 1. It consists of a solar panel, a DC-DC boost converter, a machine learning-based reference voltage estimator, a PID controller, and a Pulse Width Modulation (PWM) signal generator. The system components are explained below: 


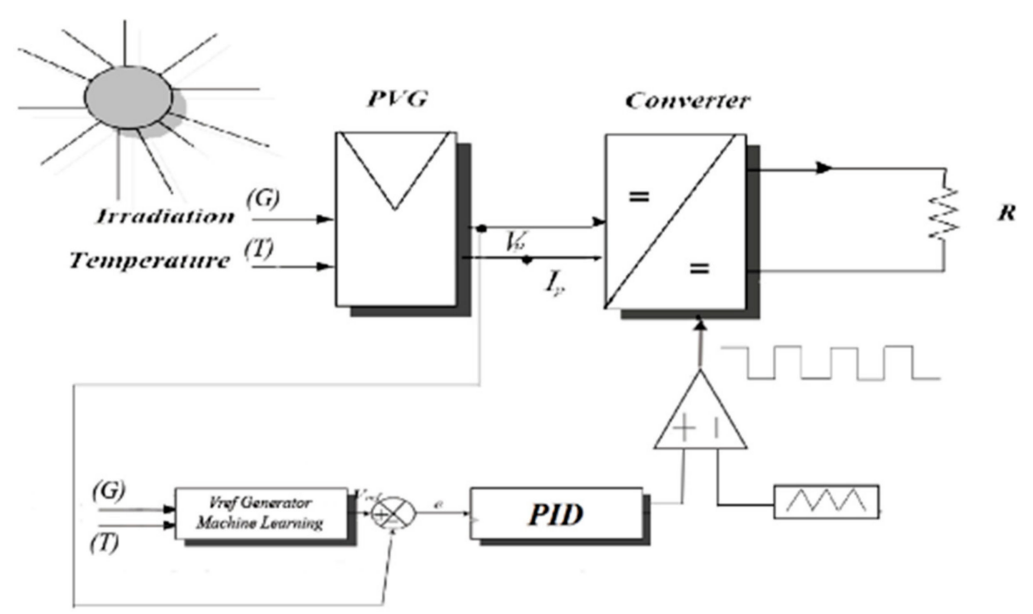

Figure 1. Proposed maximum power point tracking (MPPT) system.

\subsection{PV Panel}

The PV panel utilized in this research is a Mitsubishi TD185MF5 panel. It is characterized by 50 polycrystalline cells connected in a series configuration. A list of the PV panel specifications is given in Table 1.

Table 1. Mitsubishi TD185MF5 PV Panel characteristic.

\begin{tabular}{cc}
\hline Cell Type & Polycrystalline Silicon \\
\hline Maximum power & $185 \mathrm{~W}$ \\
Open Circuit Voltage $\left(V o_{o c c}\right)$ & $30.60 \mathrm{~V}$ \\
Short Circuit Current $\left(I_{s c}\right)$ & $8.13 \mathrm{~A}$ \\
Voltage of Max Power $\left(V_{M P P}\right)$ & $24.40 \mathrm{~V}$ \\
Current of Max Power $\left(I_{M P P}\right)$ & $7.58 \mathrm{~A}$ \\
Normal Operating Cell Temp & $47.5^{\circ} \mathrm{C}$ \\
\hline
\end{tabular}

\subsection{Machine Learning-Based Reference Voltage Estimator}

As described in [6], machine learning algorithms can be employed to predict the reference voltage accurately after being trained on historical data. In this work, we use two machine learning algorithms, namely, generalized regression neural network (GRNN) and SVR and compare the performance of the system when employing each algorithm. Both algorithms are well-known for their ability of regression, function modeling, and prediction. More details about GRNN and SVR can be found in [27-29] and [30], respectively.

Referring to Figure 1, the $V_{\text {ref }}$ generator block estimates the reference voltage accurately after being previously trained on historical data. For a given temperature-irradiation pair, it predicts $\widetilde{V}_{\text {ref }}$ that coincides with the maximum output power point of the panel. In order for the machine learning block to be fully functional, it has to pass through two stages, the learning stage (also referred to as the training stage) and the running stage (also referred to as the testing stage). The objective of the learning stage is to build and validate a function that models the relationship of temperature and irradiation with the reference voltage $V_{\text {ref }}$ using historical (training) data. The model obtained in the learning stage is then used in the running stage to predict the reference voltage value $\widetilde{V}_{\text {ref }}$ using as input testing data that the model has not seen in the learning phase. The learning and running stages are explained in Figure 2. The accuracy of the machine learning model prediction ability is measured using the root mean square error (RMSE):

$$
\text { RMSE }=\sqrt{\frac{1}{n} \sum_{i=1}^{n}\left(V_{r e f}-\widetilde{V}_{r e f}\right)^{2}}
$$


where $n$ denotes the number of testing data points, $V_{\text {ref }}$ and $\widetilde{V}_{r e f}$ denote the measured reference voltage and the machine learning predicted reference voltage, respectively.



Figure 2. Learning and Running Stages of the Machine Learning Algorithms.

The predicted voltage $\widetilde{V}_{\text {ref }}$ will be used as a reference to the PID controller to push the system to work at its optimal point at the characteristic curve. As a result, the efficiency will be improved.

\subsection{DC-DC Boost Converter}

In this work, we employ a boost converter to step-up the DC voltage at its input to the DC voltage level required by the load. In addition to an inductor and a capacitor that serve as energy storing elements, it includes a diode and a transistor for switching purposes. The input of the boost converter is connected to the solar panel and its output is connected to the load. Figure 3 shows the circuit of the DC/DC boost converter used in this research.

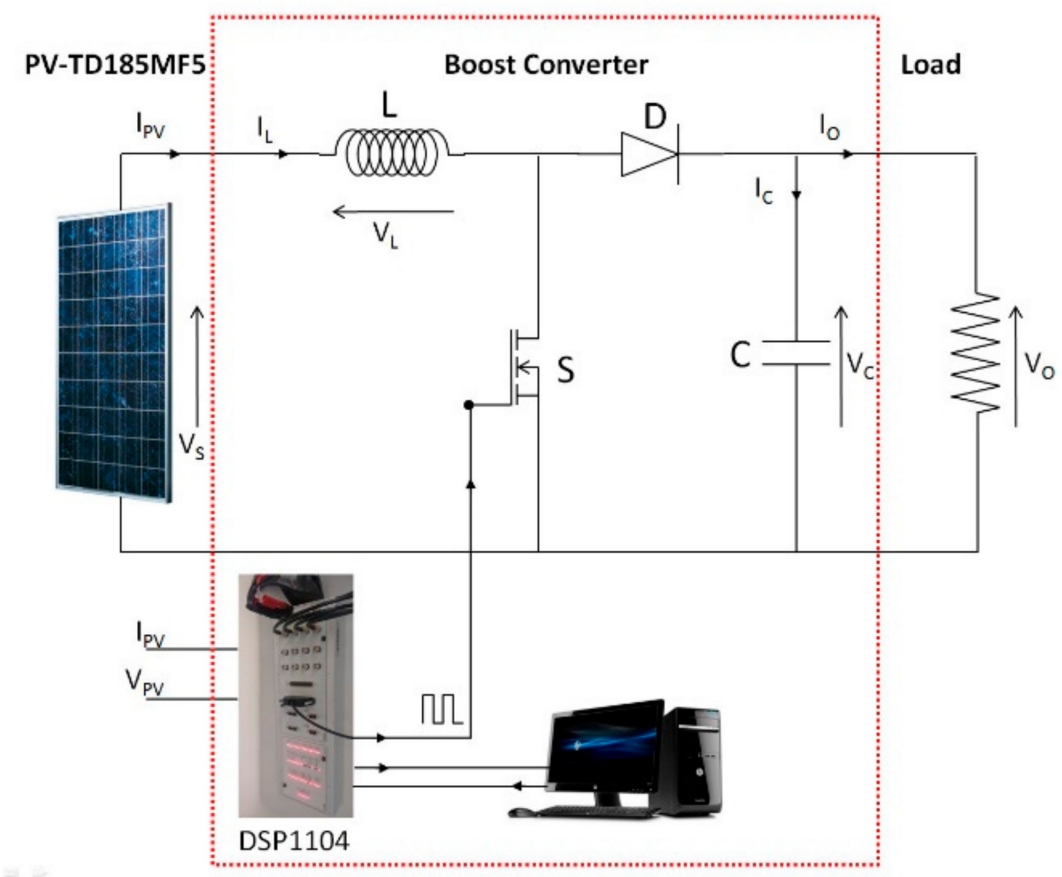

Figure 3. Boost Converter reproduced by permission from [19], Hindawi, 2016. 
The principle that the boost converter operates on is the inductor's behavior in opposing changes in the current [31]. The boost converter is mainly operating in two modes as follows:

Mode 1: Initially, the switch is closed for a duration of $D$ seconds during which the inductor stores magnetic energy as a result of the current supplied by the source. During that time, the closed switch that acts as a short-circuit together with the reverse-biased diode, isolates the inductor side of the circuit from the capacitor side. Thus, no current will be supplied to the capacitor by the source and the load current will be supplied by discharging the capacitor. The duration $D$ is controlled by the transistor which is triggered by the PID controller as shown in Figure 1.

Mode 2: The switch opens for a duration of $(1-D)$ seconds. At this point, the diode becomes forward-biased allowing the inductor to release the stored magnetic energy in the form of a current. Together with the source, the inductor charges the capacitor and meets the load demands. If properly designed, the load current remains, in the two modes, almost constant as is the case for the capacitor voltage. Since the average voltage across inductor $V_{\text {Lavg }}$ is zero:

$$
V_{\text {Lavg }}=D \cdot V_{s}+(1-D) \cdot\left(V_{s}-V_{o}\right)=0,
$$

Then

$$
V_{o} \cdot(1-D)=V_{s}+D \cdot V_{s}-D \cdot V_{s}
$$

Thus, the relation between the input voltage $V_{s}$ and the output voltage $V_{o}$ becomes:

$$
V_{o}=\frac{V_{s}}{1-D}
$$

Leading to the conclusion that $V_{o}$ is dependent on $D$ is the duty ratio.

\subsection{PID controller}

The predicted voltage $\widetilde{V}_{\text {ref }}$ will be used as a reference to the PID controller whose objective is to drive the system to work in its optimal power point, thus maximizing the solar panel output power for given temperature and irradiation values and maintaining high efficiency.

\section{Methodology}

The aim of this work is to increase the PV efficiency by estimating an accurate optimal reference voltage $\widetilde{V}_{r e f}$ via a machine learning method. The reference voltage is used as a reference for the PID controller which will work towards pushing the whole system to operate with the estimated voltage leading to maximum power harvesting and stable DC-DC boost converter output voltage as shown in Figure 1. The key for improving the system efficiency is the voltage reference generator which is supposed to estimate accurately the value of $V_{\text {ref }}$ that corresponds to the specific existing weather conditions (temperature and irradiation). The $V_{r e f}$ generators that we have chosen to use in this work are SVR and GRNN. Both SVR and GRNN are effective regression machine learning methods. The estimation performance of machine learning methods, in general, depends also on the quantity and quality of the gathered data. Therefore, an accurate data accusation system is used in this work to find the PV model $(I, V)$ under different weather conditions, thus allowing us to find the optimum operating voltage of the PV. The data accusation system is shown in Figure 4. Besides the Mitsubishi TD185MF5 panel (Mitsubishi Electric, USA), it includes an irradiance and temperature sensor (Si-420TC-T-K) (Ingenieurbüro Mencke \& Tegtmeyer GmbH, Hameln, Germany), a clamp current Chauvin Arnoux PAC 12 (Chauvin Arnoux, Toulouse, France) for direct current measurements, a programmable amplifier with insulation SINEAX TV809 (Camille Bauer, Wohlen, Switzerland) to isolate electrically the input/output signals and SINEAX CAM data logger (Camille Bauer, Wohlen, Switzerland) to record the measurements of current, voltage, temperature, and irradiance. The power values are calculated from the voltage and current readings. The experiment was conducted in 
Vitoria-Gasteiz northeast of Spain where the weather is typically cloudy or partly cloudy all year. A more detailed discussion of the components of the data acquisition system can be found in [19].

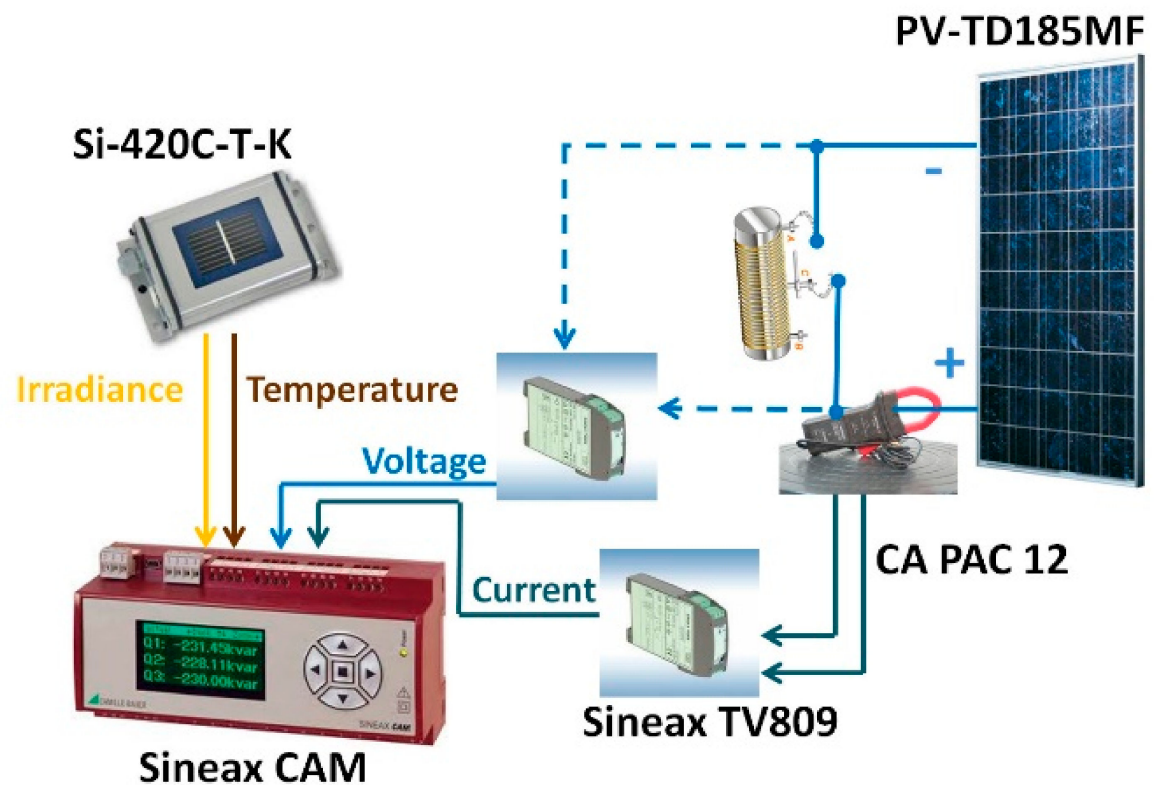

Figure 4. Data Acquisition System reproduced by permission from [19], Hindawi, 2016.

The gathered one-year-long dataset was cleaned from anomalies and divided into a training set and a testing set. For training and validation, 70\% of the data points were used. The rest was used for testing. Referring back to Figure 2, which describes the learning and running stages, it is obvious that we are implementing a supervised learning machine learning strategy where irradiation $(G)$ and temperature $(T)$ serve as inputs and $V_{\text {ref }}$ as a target. As a result of the learning stage, a function $\widetilde{V}_{r e f}=f(G, T)$ is obtained. It models the relationship of $G, T$ with $V_{\text {ref }}$. The function $\widetilde{V}_{\text {ref }}=f(G, T)$ is utilized in the running stage to predict the reference voltage $\widetilde{V}_{\text {ref }}$ for new inputs $G$ and $T$. The SVR setup of our work uses a radial basis function (RBF) kernel. Similarly, GRNN has a radial basis layer.

The overall maximum power tracking system, shown in Figure 1, was implemented using MATLAB Simulink environment. The first step of the system implementation involved training, validating, and testing the machine learning block offline without being connected to any other system components. Once it became capable of estimating $V_{\text {ref }}$ accurately, the trained SVM was then implemented in Simulink using the MATLAB function block. The PV panel and the DC-DC converter were also modeled in the Simulink environment using their characteristic equations. All the above-mentioned components were connected to a PID block and a variable load. The performance of the proposed system was observed against variations in temperature, irradiance, and load. The simulation results are discussed in the following Section 4.

\section{Results and Discussion}

In this section, we evaluate the ability of the PID controller to push the system to operate at the reference voltage predicted by the trained machine learning algorithm.

First, we show in Figures 5 and 6 the PV characteristics obtained from the measured data for different irradiances and two temperatures values, namely, $5^{\circ} \mathrm{C}$ and $10^{\circ} \mathrm{C}$. The red curves shown are the $V_{\text {ref }}$ curves corresponding to the maximum power point $\left(V_{M P P}=f\left(P_{\max }\right)\right)$. 


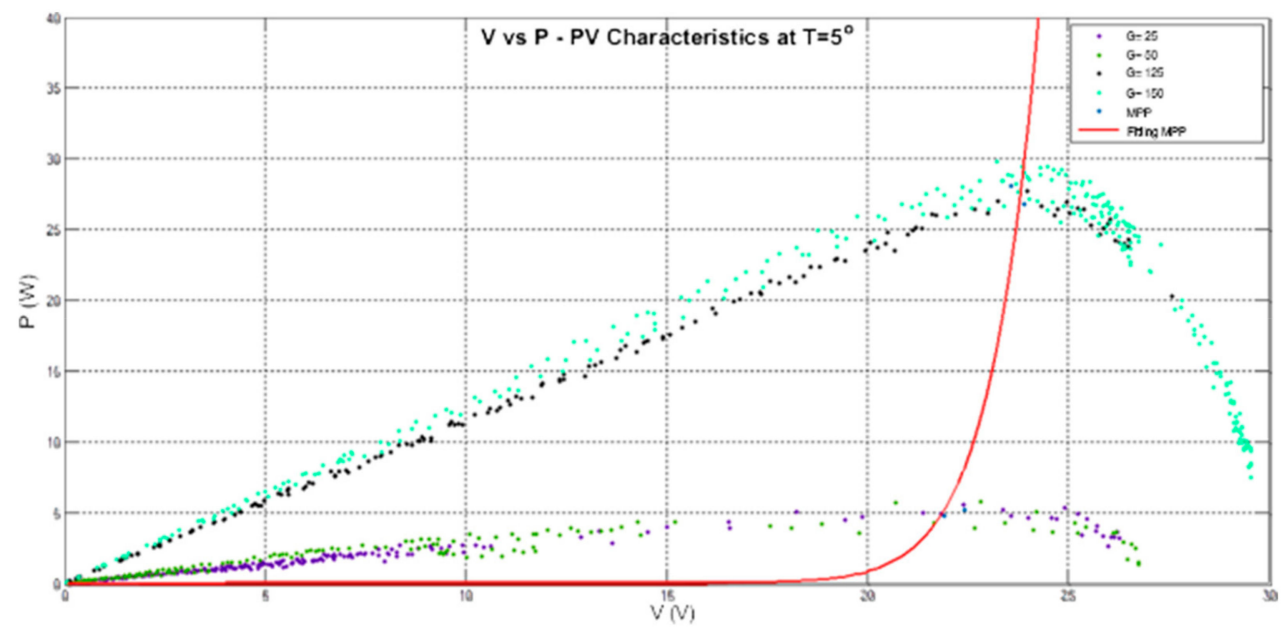

Figure 5. MPPT Curve at $\mathrm{T}=5{ }^{\circ} \mathrm{C}$.

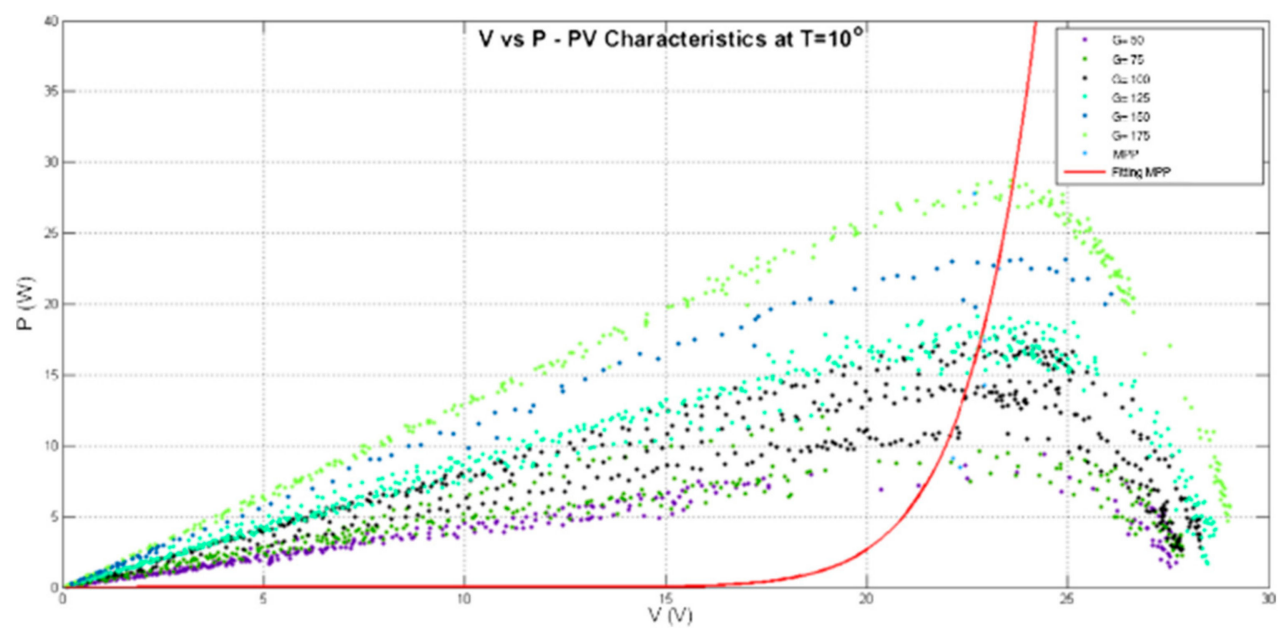

Figure 6. MPPT Curve at $\mathrm{T}=10^{\circ} \mathrm{C}$.

A surface that shows the behavior of PV naximum power point tracking as a function of voltage and temperature $\left(V_{M P P}=f(P, T)\right)$ is shown in Figure 7. Figure 7 is obtained from Figures 5 and 6 .

The results demonstrate the ability of the machine learning algorithm to correctly predict $V_{\text {ref }}$, and the maximum power as a function of temperature and irradiation for both SVR and GRNN are given in Figures 8-11. It can be visually seen from Figures 8-11 that both algorithms result in accurate predictions as the estimated data coincide with the measured data. A quantitative comparison in terms of RMSE between the two algorithms is given in Table 2. It can be seen from Table 2 that SVR outperforms GRNN as it results in less RMSE between the measured and predicted values. A similar conclusion was made in [32] where it was shown that SVR resulted in better rainfall forecasting than GRNN did. Since SVR in our experiment has provided a more accurate estimation of the measured values of $V_{r e f}$, we adopt in our proposed MPPT system SVR as the machine learning-based reference voltage estimator block. 
Surface power-temperature-voltage characteristic of maximum power point (MPP)

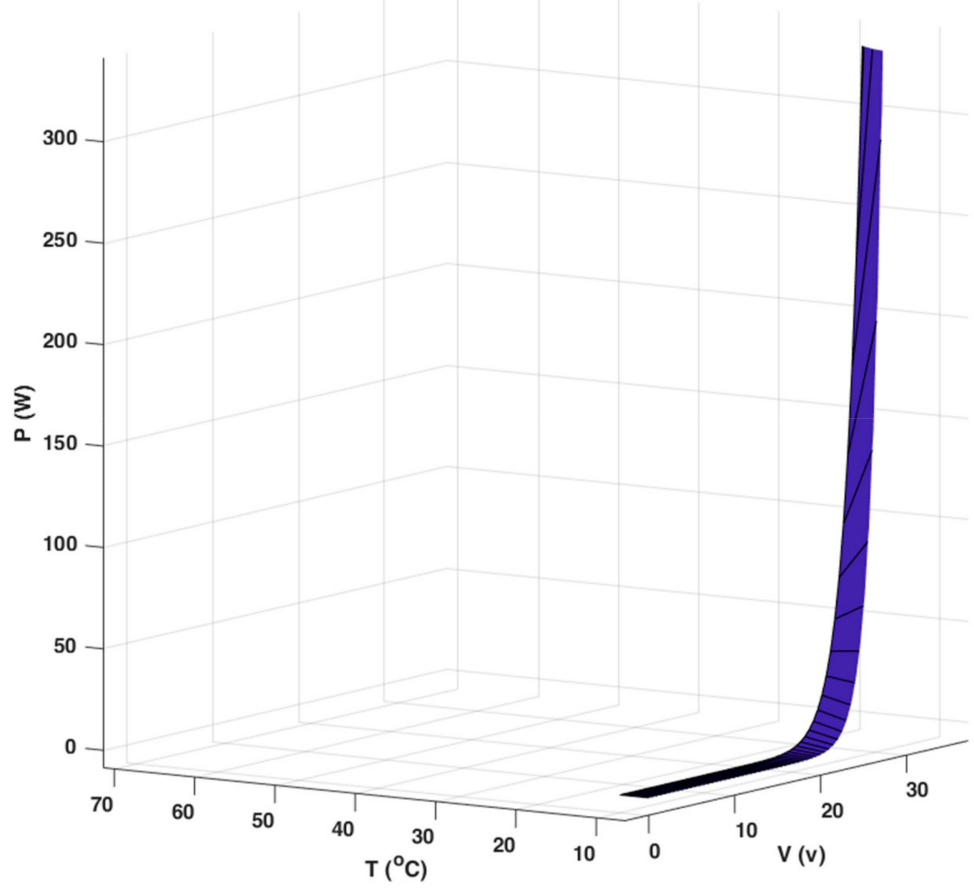

Figure 7. Surface power-temperature-voltage characteristics of maximum power point (MPP).

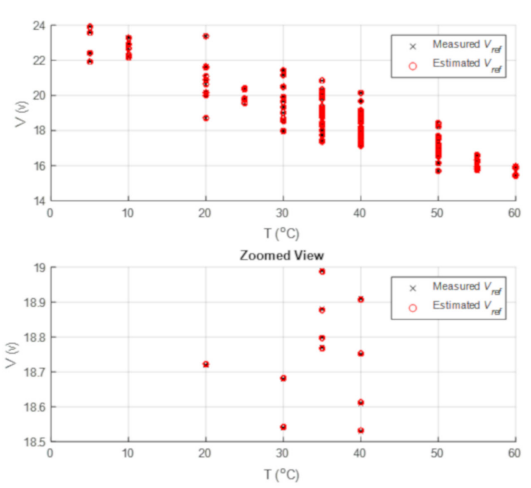

(a)

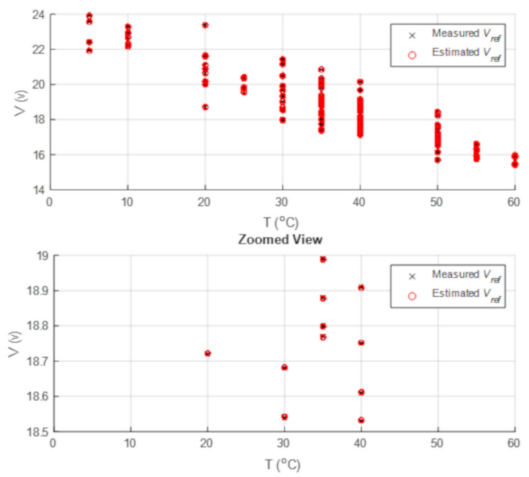

(b)

Figure 8. Predicted and measured $V_{\text {ref }}$ for different temperature values using: (a) SVR; (b) GRNN.

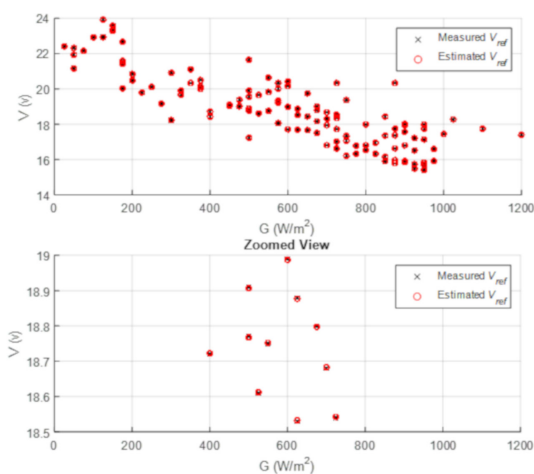

(a)

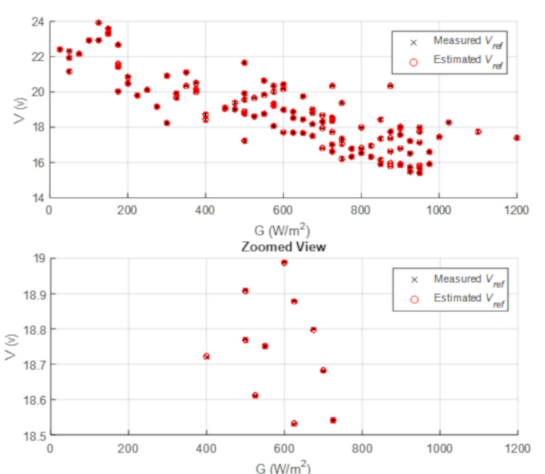

(b)

Figure 9. Predicted and measured $V_{\text {ref }}$ for different irradiation levels using: (a) SVR; (b) GRNN. 

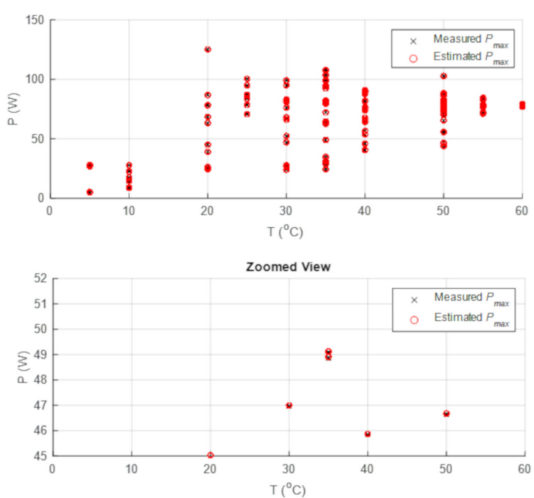

(a)
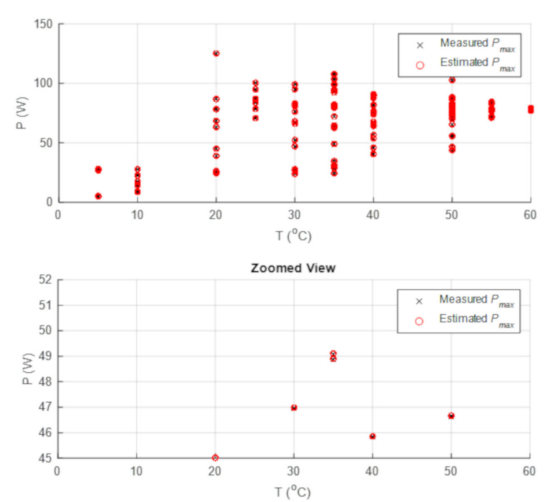

(b)

Figure 10. Predicted and measured $P_{\max }$ for different temperature values using: (a) SVR; (b) GRNN.
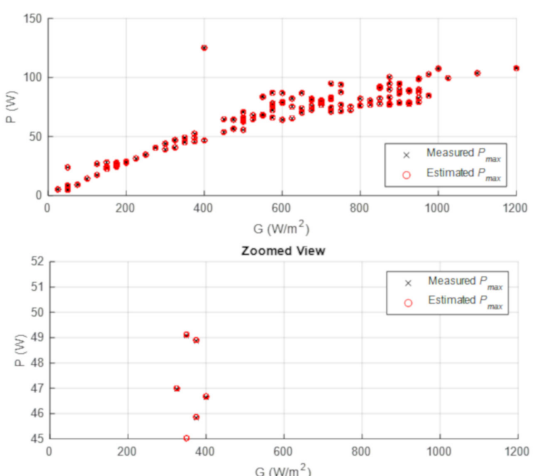

(a)


(b)

Figure 11. Predicted and measured $P_{\max }$ for different irradiation levels using: (a) SVR; (b) GRNN.

Table 2. RMSE in both machine learning algorithms.

\begin{tabular}{ccc}
\hline Machine Learning Algorithm & RMSE in $V_{\text {ref }}(V)$ & RMSE in $\boldsymbol{P}_{\max }(\mathbf{W})$ \\
\hline SVR & 0.0023 & 0.0278 \\
GRNN & 0.0246 & 0.044 \\
\hline
\end{tabular}

The proposed system's ability to push the PV panel to work at $V_{\text {ref }}\left(V_{M P P}\right)$ and produce $P_{\max }$ at different values of temperatures, irradiance, and different loads is demonstrated in Figures 12-16. Figure 12 shows that the PID regulator pushes the output voltage of the PV system to work with the needed $\widetilde{V}_{M P P}$.

For example, at $G=500 \mathrm{~W} / \mathrm{m}^{2}$ and $T=290 \mathrm{Kelvin}, \widetilde{V}_{M P P}=V_{\mathrm{PV}}=18.77 \mathrm{~V}$ and $P=70 \mathrm{~W}$. A zoomed version of Figure 12 is shown in Figure 13. It shows that by using our MPPT algorithm and PID regulator, the system works at desired $\widetilde{V}_{M P P}$. The error between the estimated $\widetilde{V}_{M P P}$ and the output voltage of the PV system is minimal.

Figure 14 shows that the percentage error between estimated $\widetilde{V}_{M P P}$ and the output voltage of the PV system is very low, which means that the efficiency of the system has improved with the use of the PID regulator. At $t=3 \mathrm{~h}$ the temperature $T$ changed from 290 to $310 \mathrm{~K}$. Thus, the $V_{M P P}$ changed from 18 to $21 \mathrm{~V}$. An overshoot fluctuation occurs at this point and then it stabilizes. 



Figure 12. The proposed system performance with variations in variable temperatures, irradiances, and different loads.

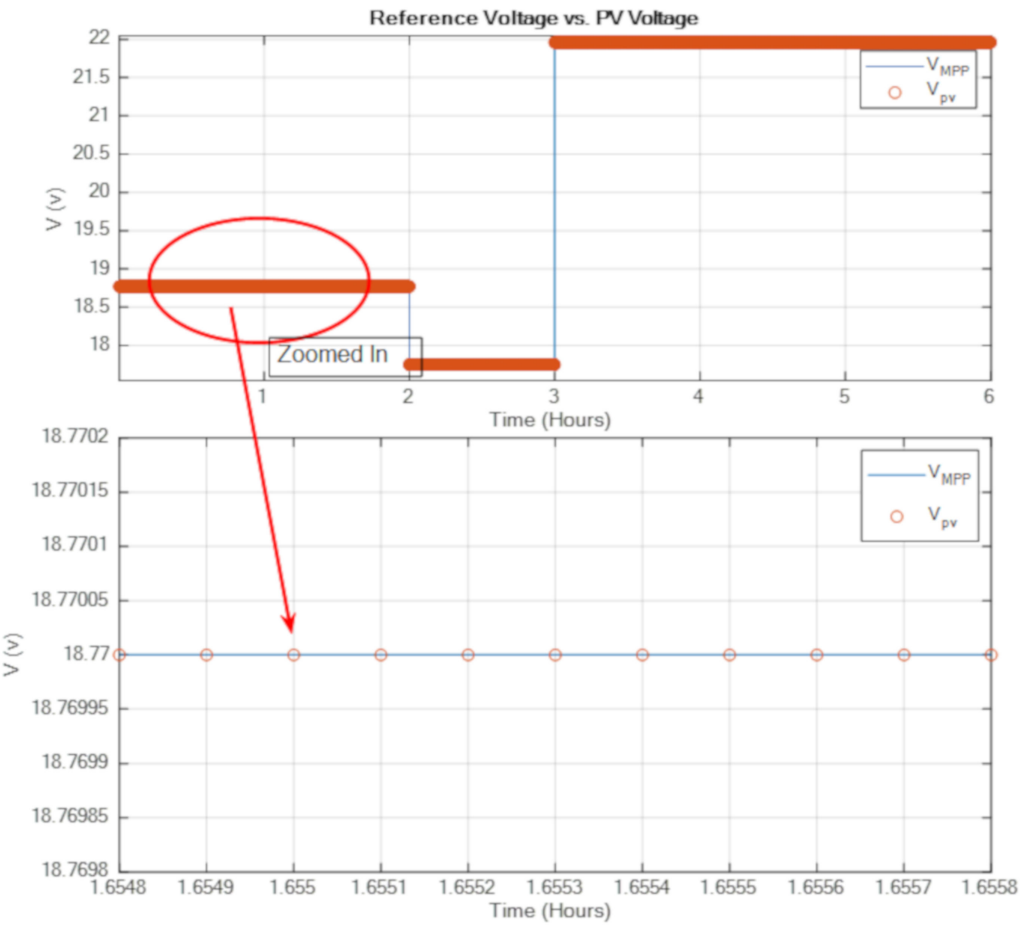

Figure 13. PID regulator pushes $V_{\mathrm{PV}}$ to follow $\widetilde{V}_{M P P}$. 


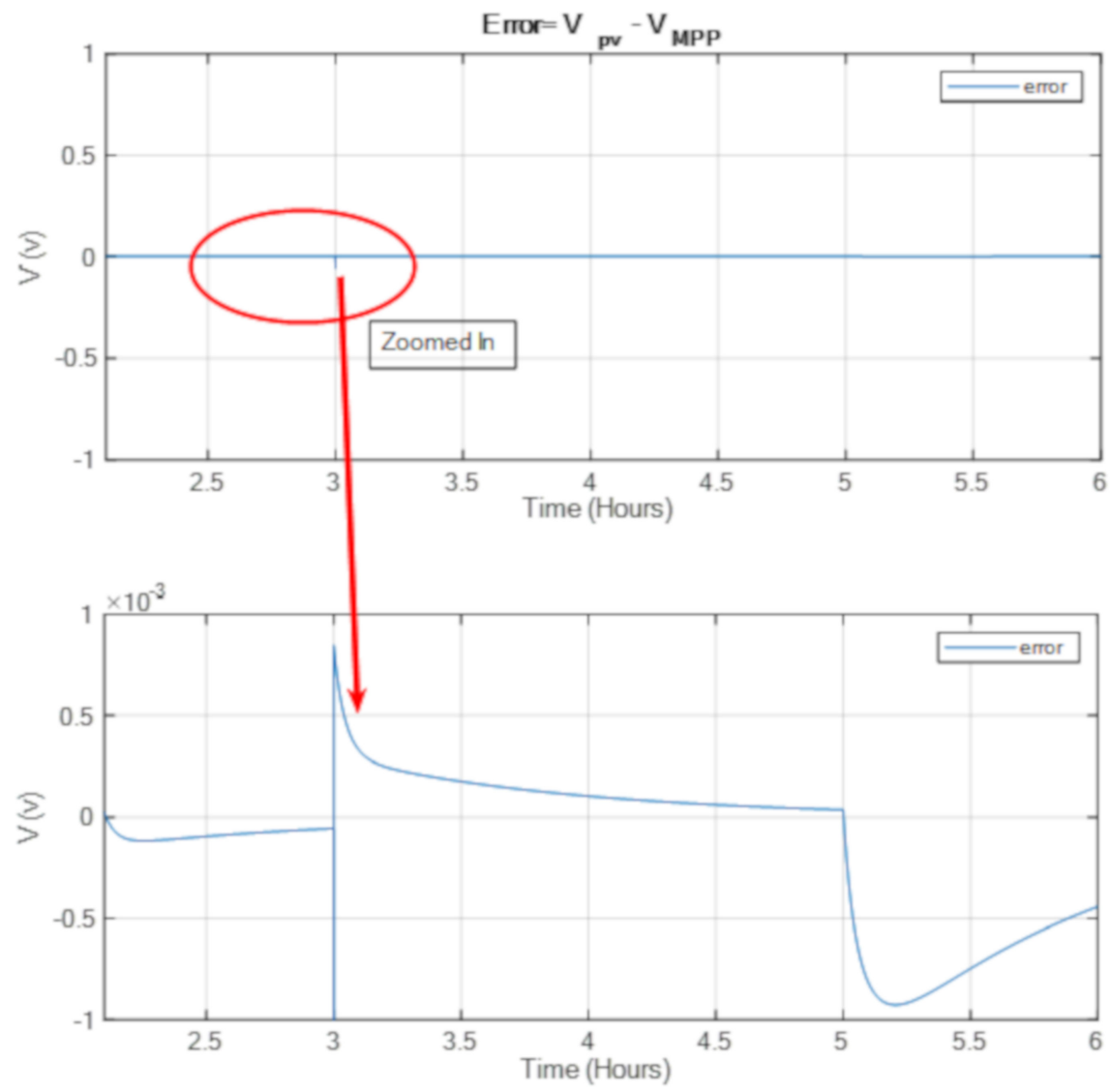

Figure 14. Error $=V_{P V}-\widetilde{V}_{M P P}$.


Figure 15. Output Power without Regulator for $R=10 \Omega$. 

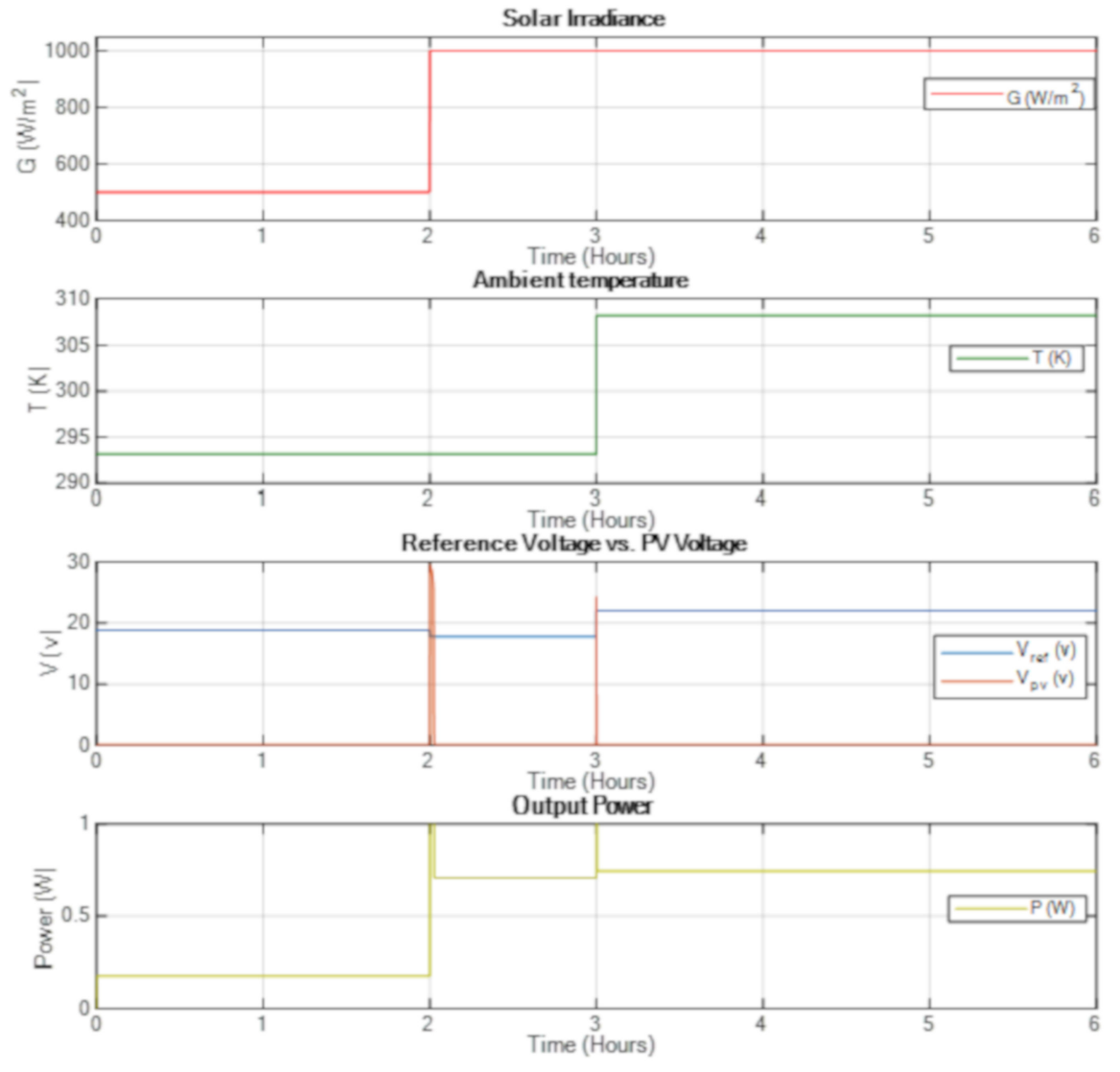

Figure 16. Output Power without Regulator for $R=100 \Omega$.

The effect of changing the load on the system with and without regulation is shown in Figures 15 and 16. Figures 15 and 16 show the system response when there is no regulation for $R=10 \Omega$ and 100 $\Omega$, respectively. It can be seen that the output power is dependent on the load. Thus, the system is not robust without using the PID regulator.

Referring back to Figure 12 where the system is controlled by a PID controller (with $V_{\text {ref }}$ predicted by the machine learning block), it can be clearly seen that the output power is not affected by the load. It is only dependent on $T$ and $G$. Comparing to Figures 15 and 16, the output power is improved from $0.2 \mathrm{~W}$ when there is no regulation, to $200 \mathrm{~W}$ with regulation. As a result, it can be seen that the PID controller with reference voltage obtained from the machine learning block is able to provide a stable output voltage and maximized power.

\section{Conclusions}

This paper has studied the conditions at which the maximum power point of a PV panel is obtained. It showed that the maximum power point is very sensitive to external disturbances such as temperature and irradiation. It introduced a novel method for maximizing the output power of a PV panel when connected to a DC/DC boost converter under variable load conditions. Machine learning strategies were used to predict the optimum reference voltage of the PV panel at all-weather conditions to serve as a reference for a PID controller that ensured that the DC/DC boost converter provided a stable output voltage and maximum power under different weather conditions and loads. The proposed system was tested on an experimental photovoltaic dataset gathered from Spain. It showed robustness against internal and external disturbances. The paper also showed that the SVM based reference voltage generator performed better than that based on GRNN.

In the future, other aspects that disturb the PV systems power generation efficiency such as humidity, dust, and fog among others will be considered in the machine learning model which will 
probably increase prediction accuracy. Moreover, the experiment will be conducted in areas other than northeast Spain that are characterized by warmer or cooler climates to check how the proposed system works under different climatic conditions.

Author Contributions: Conceptualization, M.T., M.F. and O.B.; methodology, M.T., M.F., O.B. and J.A.R.-H.; investigation, M.T., M.F., O.B. and J.A.R.-H.; software, M.T., M.F. and M.J.T.; validation, M.T., M.F., M.J.T. and M.B.; formal analysis, M.T., M.F., M.J.T., H.A and M.A.S.; writing-original draft preparation, M.T., M.F., M.J.T., H.A., M.A.S. and M.B.; writing—review \& editing, M.T., M.F., O.B.; visualization, M.T., M.F., M.J.T. and J.A.R.-H. All authors have read and agreed to the published version of the manuscript.

Funding: This research received no external funding.

Acknowledgments: The authors wish to express their gratitude to the Basque Government through the project SMAR3NAK (ELKARTEK KK-2019/00051), to the Diputación Foral de Álava (DFA) through the project CONAVAUTIN 2 and to the UPV/EHU for supporting this work.

Conflicts of Interest: The authors declare no conflict of interest.

\section{References}

1. Abas, N.; Kalair, A.; Khan, N. Review of fossil fuels and future energy technologies. Futures 2015, 69, 31-49. [CrossRef]

2. Dollinger, B.; Dietrich, K. Storage systems for integrating wind and solar energy in Spain. In Proceedings of the International Conference on Renewable Energy Research and Applications (ICRERA), Madrid, Spain, 20-23 October 2013.

3. Farhat, M.; Barambones, O.; Sbita, L. Efficiency optimization of a DSP-based standalone PV system using a stable single input fuzzy logic controller. Renew. Sustain. Energy Rev. 2015, 49, 907-920. [CrossRef]

4. Jie, S.; Lee, W.J. Forecasting Power Output of Photovoltaic Systems Based on Weather Classification and Support Vector Machine. IEEE Trans. Ind. Alications 2012, 48, 1064-1069. [CrossRef]

5. Huang, Y.; Lu, J.; Liu, C.; Xu, X.; Wang, W.; Zhou, X. Comparative study of power forecasting methods for PV stations. In Proceedings of the 2010 International Conference on Power System Technology, Hangzhou, China, 24-28 October 2010. [CrossRef]

6. Takruri, M.; Farhat, M.; Sunil, S.; Ramos-Hernanz, J.A.; Barambones, O. Suort Vector Machine for Photovoltaic System Efficiency Improvement. J. Sustain. Dev. Energy Water Environ. Syst. 2019. [CrossRef]

7. Farhat, M.; Barambones, O.; Sbita, L. A new maximum power point method based on a sliding mode aroach for solar energy harvesting. Alied Energy 2017, 185, 1185-1198.

8. De Brito, M.A.G.; Galotto, L.; Sampaio, L.P.; Melo, G.D.A.E.; Canesin, C.A. Evaluation of the Main MT Techniques for Photovoltaic Alications. IEEE Trans. Ind. Electron. 2013, 60, 1156-1167. [CrossRef]

9. Veerachary, M.; Senjyu, T.; Uezato, K. Neural-network-based maximum-power-point tracking of coupled-inductor interleaved-boost-converter-sulied pv system using fuzzy controller. IEEE Trans. Ind. Electron. 2003, 50, 749-758. [CrossRef]

10. Sheik, S.; Devaraj, D.; Imthias, T. A novel hybrid Maximum Power Point Tracking Technique using Perturb \& Observe algorithm and Learning Automata for solar PV system. Energy 2016, 112, 1096-1106.

11. Piegari, L.; Rizzo, R.; Spina, I.; Tricoli, P. Optimized Adaptive Perturb and Observe Maximum Power Point Tracking Control for Photovoltaic Generation. Energies 2015, 8, 3418-3436. [CrossRef]

12. Chen, Y.; Jhang, Y.; Liang, R. A fuzzy-logic based auto-scaling variable step-size MT method for PV systems. Solar Energy 2016, 126, 53-63. [CrossRef]

13. Alajmi, B.N.; Ahmed, K.H.; Finney, S.J.; Williams, B.W. Fuzzy-Logic-Control Aroach of a Modified Hill-Climbing Method for Maximum Power Point in Microgrid Standalone Photovoltaic System. IEEE Trans. Power Electron. 2011, 26, 1022-1030. [CrossRef]

14. Robles Algarín, C.; Taborda Giraldo, J.; Rodríguez Álvarez, O. Fuzzy Logic Based MT Controller for a PV System. Energies 2017, 10, 2036. [CrossRef]

15. Hassan, S.Z.; Li, H.; Kamal, T.; Arifoglu, U.; Mumtaz, S.; Khan, L. Neuro-Fuzzy Wavelet Based Adaptive MT Algorithm for Photovoltaic Systems. Energies 2017, 10, 394. [CrossRef]

16. Hou, W.; Jin, J.; Zhu, C.; Li, G. A Novel Maximum Power Point Tracking Algorithm Based on Glow worm Swarm Optimization for Photovoltaic Systems. Int. J. Photoenergy 2016, 2016, 1-9. [CrossRef] 
17. Titri, S.; Larbes, C.; Youcef, K.; Benatchba, K. A new MT controller based on the Ant colony optimization algorithm for Photovoltaic systems under partial shading conditions. Alied Soft Comput. 2017, 58, 465-479. [CrossRef]

18. Messalti, S.; Harrag, A.; Loukriz, A. A new variable step size neural networks MT controller: Review, simulation and hardware implementation. Renew. Sustain. Energy Rev. 2017, 68, 221-233. [CrossRef]

19. Ramos-Hernanz, J.A.; Barambones, O.; Lopez-Guede, J.M.; Zamora, I.; Eguia, P.; Farhat, M. Sliding Mode Real-Time Control of Photovoltaic Systems Using Neural Estimators. Int. J. Photoenergy 2016, 2016, 1-16. [CrossRef]

20. Kofinas, P.; Dounis, A.; Papadakis, G.; Assimakopoulos, M. An Intelligent MT controller based on direct neural control for partially shaded PV system. Energy Build. 2015, 90, 51-64. [CrossRef]

21. Bouarroudj, N.; Boukhetala, D.; Feliu-Batlle, V.; Boudjema, F.; Benlahbib, B.; Batoun, B. Maximum Power Point Tracker Based on Fuzzy Adaptive Radial Basis Function Neural Network for PV-System. Energies 2019, 12, 2827. [CrossRef]

22. Wu, Q.; Peng, C. Wind Power Generation Forecasting Using Least Squares Suort Vector Machine Combined with Ensemble Empirical Mode Decomposition, Principal Component Analysis and a Bat Algorithm. Energies 2016, 9, 261. [CrossRef]

23. Esen, H.; Ozgen, F.; Esen, M.; Sengur, A. Modelling of a new solar air heater through least-squares suort vector machines. Expert Syst. Alications 2009, 36, 10673-10682. [CrossRef]

24. Chen, J.L.; Liu, H.B.; Wu, W.; Xie, D.T. Estimation of monthly solar radiation from measured temperatures using suort vector machines-A case study. Renew. Energy 2011, 36, 413-420. [CrossRef]

25. Ekici, B.B. A least squares suort vector machine model for prediction of the next day solar insolation for effective use of PV systems. Measurement 2014, 50, 255-262. [CrossRef]

26. Burges, C.J.C.; Crisp, D.J. Uniqueness of the SVM solution. In Advances in Neural Information Processing; Jordan, M.I., Leen, T.K., Muller, K.-R., Eds.; MIT Press: Cambridge, MA, USA, 2000; Volume 12, pp. $223-229$.

27. Al-Mahasneh, A.J.; Anavatti, S.; Garratt, M.; Pratama, M. Applications of General Regression Neural Networks in Dynamic Systems. In Digital Systems; Asadpour, V., Ed.; Intech Open: London, UK, 2018. [CrossRef]

28. Al-Mahasneh, A.J.; Anavatti, S.G.; Garratt, M.A. Review of applications of generalized regression neural networks in identification and control of dynamic systems. arXiv 2018, arXiv:1805.11236.

29. Specht, D.F. A general regression neural network. IEEE Trans. Neural Netw. 1991, 2, 568-576. [CrossRef]

30. Takruri, M.; Rajasegarar, S.; Challa, S.; Leckie, C.; Palaniswami, M. Spatio-Temporal Modelling Based Drift Aware Wireless Sensor Networks. IET Wirel. Sens. Syst. 2011, 1, 110-122. [CrossRef]

31. Hua, C.; Shen, C. Study of maximum power tracking techniques and control of DC/DC converters for photovoltaic power system. PESC 98 Record. In Proceedings of the 29th Annual IEEE Power Electronics Specialists Conference (Cat. No.98CH36196), Fukuoka, Japan, 22 May 1998. [CrossRef]

32. Lu, W.; Chu, H.; Zhang, Z. Alication of generalized regression neural network and suort vector regression for monthly rainfall forecasting in western Jilin Province, China. J. Water Suly Res. Technol. Aqua. 2015, 64, 95-104. [CrossRef]

(C) 2020 by the authors. Licensee MDPI, Basel, Switzerland. This article is an open access article distributed under the terms and conditions of the Creative Commons Attribution (CC BY) license (http://creativecommons.org/licenses/by/4.0/). 